\title{
Consumption, House Prices and Collateral Constraints: a Structural Econometric Analysis
}

\author{
Matteo Iacoviello* \\ Boston College
}

September 13, 2004

*Email: iacoviel@bc.edu. Phone: +1-617-552-3689. Fax:+1-617-552-2308. Address: Department of Economics, Boston College, 140 Commonwealth Avenue, Chestnut Hill, MA 02467, USA. I thank Fabio Schiantarelli, the editors Robert H. Edelstein and Kyung-Hwan Kim, an anonymous referee and seminar participants at the Chinese University of Hong Kong and the SED 2004 meetings for comments and suggestions. Massimo Giovannini provided excellent research assistance. 


\begin{abstract}
If borrowing capacity of indebted households is tied to the value of their home, house prices should enter a correctly specified aggregate Euler equation for consumption. I develop a simple two-agent, dynamic general equilibrium model in which home (collateral) values affect debt capacity and consumption possibilities for a fraction of the households. I then derive and estimate an aggregate consumption Euler equation, and estimate its structural parameters. The results provide robust support for housing prices as a driving force of consumption fluctuations.
\end{abstract}

Keywords: Consumption; Credit; Collateral Constraints; House Prices.

JEL Classification: C2, E2, G1, R2. 


\section{Introduction}

The log-linear version of the Euler equation for consumption for a representative agent who can freely borrow and lend is:

$$
c_{t}=E_{t} c_{t+1}-\sigma r_{t}
$$

where $c_{t}$ is the $\log$-deviation of consumption at time $t$ from its steady state value, $E_{t} c_{t+1}$ is its expected value conditional on information at time $t, r_{t}$ is the change in the real short-term interest rate, and $\sigma$ is the constant intertemporal elasticity of substitution for the class of preferences displaying constant relative risk aversion. This equation is the first-order approximation to the optimality condition for a lifetime maximization problem subject to a sequence of intertemporal budget constraints. ${ }^{1}$

At least since Campbell and Mankiw (1989) and Jappelli and Pagano (1989), various researchers have tried to estimate the above equation for consumption: $(a)$ using aggregate time series data; $(b)$ adding other explanatory variables besides expected consumption and interest rates on the right-hand side of the equation $(1.1){ }^{2}$

Using aggregate time series data has the benefit of giving quantitative evidence on the aggregate time series properties of consumption, as well as the advantage of providing a direct test for models that rely on the assumption of a representative agent and complete markets. Adding other explanatory variables to the right-hand side of (1.1) can test whether all agents in the economy behave according to the life-cycle model and/or whether they face any additional constraint besides the intertemporal budget constraint. For instance, Campbell and Mankiw (1989) estimate a version of (1.1) adding income growth to the set of regressors. Their justification is that if some agents behave according to the simple rule $C_{t}=Y_{t}$, where $C_{t}$ and $Y_{t}$ are current period consumption and income, then the coefficient on income growth should capture the fraction of so-called rule-of-thumb consumers.

The insight of the above mentioned studies is that aggregate time-series consumption is thought of as the result of the aggregate of two different types of consumers. However, describing rule-of-thumb consumers

\footnotetext{
${ }^{1}$ See Carroll (2001) for a discussion. Carroll refers to equation 1.1 as the 'crude' approximation. A more precise secondorder approximation would involve the expectation of the square of consumption growth, which is vanishingly small only when uncertainty is small or when $\sigma$ is very large.

${ }^{2}$ Hall (1978) first tested the implications of the above model using time-series data. His emphasis was mostly on $(a)$.
} 
in the naive way $C_{t}=Y_{t}$ may omit important aspects of the reality. Consumers are actually inundated by offers of car loans, credit cards, home equity loans, and so on. For example, as of 2003, homeowners had $\$ 315$ billion in outstanding debt from home equity lines of credit. Most of these loans require the borrower to post some collateral, and it is widely acknowledged that housing equity represents, in most economies, the largest form of collateral. ${ }^{3}$

In addition, several commentators have expressed the consideration that rising house prices in the US and Europe have kept consumption growth high throughout the 1990's. ${ }^{4}$ A high elasticity of consumption to house prices, which is the implicit assumption in this consideration, is hard to reconcile with the traditional life-cycle model. Think about the simplest possible case, namely an exogenous increase in house prices. If the gains were equally distributed across all population, if all agents had the same propensity to consume and if all agents were to spend these gains on housing, total wealth less housing wealth would remain unchanged, and so would the demand for non-housing consumption. ${ }^{5}$ However, if liquidity constrained households value current consumption a lot (which might explain why they became liquidity constrained in the first place) they may be able to increase their borrowing and consumption more than proportionally when the value of their home rises, so that increases in house prices might have effects on aggregate demand.

I embed these considerations into a simple model of aggregate consumption in an economy with collateral constraints tied to home values. My aim is to derive a properly specified, microfounded aggregate Euler equation for consumption, test it using aggregate time series data and identify its structural parameters. The main results are as follows: I find strong and compelling evidence for the presence of collateral effects in the consumption Euler equation. Such strong effects are the combined result of two findings: first, I estimate a non-negligible presence of constrained consumers in the Euler equation (between $20 \%$ and $25 \%$ of total consumption); second, I estimate a strong feedback from collateral values to consumption dynamics, through the effect that they generate on borrowing.

\footnotetext{
${ }^{3}$ See for instance Black et al. (1996).

${ }^{4}$ See e.g. The Economist, "Home is where the wealth is.", September 1, 2001.

${ }^{5}$ See Parker (2000) for a nice discussion of these issues.
} 


\section{Literature review}

My paper relates to a large body of literature on consumption which has used extensively intertemporal consumption Euler equations to estimate structural parameters of a model and to test the restrictions implied by such a model: see Attanasio and Low (2004) for an extensive discussion. Since Hall's (Hall, 1978) contribution, the Euler equation has been applied to both micro and macro data to fit a variety of preference specifications in different contexts.

Campbell and Mankiw $(1989,1991)$ estimate an Euler equation augmented by the presence of liquidityconstrained consumers: they argue that if some consumers simply consume out of their current income, then an appropriate specification of the consumption Euler equation should include income among the set of the regressors. The coefficient on income should then capture both the degree of excess sensitivity of consumption to current income and the income share of agents who face liquidity constraints.

Jappelli and Pagano (1989) extend the Campbell and Mankiw approach to relate the share of liquidity constrained consumers across seven industrialized countries to the size of the consumer market for debt. They find that consumption exhibits the highest sensitivity to current income in countries where the size of the consumer market debt is small, with the U.K. being the only exception. A similar approach is also undertaken by Bacchetta and Gerlach (1997), who present international evidence showing that financial variables may help predicting consumption.

Bandiera et al. (2000) estimate a similar aggregate Euler equation in a sample of developing countries, allowing for the share of constrained agents to change over time. Caporale and Williams (2001) also allow for a time-varying share of constrained consumers, but their focus is mainly on the estimation of a consumption function, rather than on the estimate of the structural parameters of the consumption Euler equation.

None of the above studies explicitly links liquidity constraints to observable variables: however, to the extent that lenders base the decision of how much to lend on some of the characteristics of the borrowers, like tangible assets, one should expect that house prices enter a correctly specified aggregate Euler equation. ${ }^{6}$ Despite this, all the studies that introduce housing wealth or housing prices in consumption equations do

\footnotetext{
${ }^{6}$ An exception is Chah et al. (1995), who derive and test using aggregate data an intertemporal Euler equation in presence of liquidity constraints tied to the stock of durable goods. They show how liquidity constraints imply a distinctive intertemporal relationship between durable and nondurable goods consumption.
} 
so by adding housing ad hoc in otherwise standard specifications, and their main focus is to measure the elasticity of consumption to housing wealth. For the US, Case et al. (2003) find long-run elasticities of consumption to house prices around 0.06 using panel data on individual US states. Davis and Palumbo (2001) estimate a long-run elasticity of consumption to housing wealth of 0.08. Carroll (2004) reports a similar number.

The emphasis of this paper is twofold. On the one hand, I use a general equilibrium model to derive an aggregate Euler equation containing house prices. On the other hand, I use the derived Euler equation to estimate its parameters, unlike previous studies that have added ad hoc housing wealth into aggregate consumption functions. ${ }^{7}$

\section{A model of consumption, house prices and liquidity constraints}

The above considerations make it clear that it is difficult to make precise inferences about the factors linking house price movements and their effects on consumption in absence of a general equilibrium model. This section presents such a model. In doing so, it also emphasizes an important channel of transmission that has been addressed by the recent literature, namely the "financial accelerator". ${ }^{8}$ The basic idea goes as follows: changes in the market value of houses affect the borrowing capacity of indebted households and, therefore, the availability of loans. Therefore an increase in residential property prices permits households to borrow and to spend more. This way, changes in house prices can have effects on aggregate demand.

I consider a perfect foresight, discrete time, infinite horizon, endowment economy, populated by constrained and unconstrained agents, both infinitely lived and of measure, respectively, $1-\zeta$ and $\zeta$.

Let me discuss in turn the working assumptions.

1. The term "unconstrained" households refers to the group which has a lower discount rate than the other. Although I define agents as constrained and unconstrained from the start, agents will be endogenously constrained and unconstrained, as will be explained below.

\footnotetext{
${ }^{7}$ Some papers have introduced housing in dynamic general equilibrium models with a representative agent. See e.g. Davis and Heathcote (2003), who examine the business cycle properties of an RBC model with a construction sector, and Piazzesi et al. (2003), who analyze the implication of housing and non-housing consumption for the prices of financial assets. ${ }^{8}$ See e.g. Bernanke and Gertler (1995), Iacoviello (2002) and Aoki et al. (2001).
} 
2. Both agents receive in each period some exogenous perishable endowment $Y_{t}$. They have preferences defined over consumption $C$ and housing $H$.

3. Aggregate housing is normalized to some constant and is in constant supply. However, shifts in housing demand across the two groups will affect housing prices as well as the allocation of housing between unconstrained and constrained agents.

4. All agents can trade houses, the consumption good, and a riskless bond.

\subsection{Unconstrained households}

Unconstrained households maximize a standard lifetime utility function given by:

$$
\max E_{0} \sum_{t=0}^{\infty} \beta^{t}\left(\frac{\left(C_{t}^{u}\right)^{1-\frac{1}{\sigma}}}{1-\frac{1}{\sigma}}+j^{u} u\left(H_{t}^{u}\right)\right)
$$

for all $t \geq 0 . E_{0}$ denotes expectations formed at date $0,{ }^{9} \beta$ is the discount factor, $\sigma$ is the intertemporal elasticity of substitution, $j^{u}$ is the relative weight on housing services in the utility function. Households derive utility from consumption $C_{t}^{u}$ and housing $H_{t}^{u}$ (priced at $Q_{t}$ ), receive a random endowment $Y_{t}^{u}$, lend in real terms $-B_{t}^{u}$, receive back $R_{t-1} B_{t-1}^{u}$, where $R_{t-1}$ is the real interest rate paid on loans made between $t-1$ and $t$.

Their flow of funds is:

$$
C_{t}^{u}+Q_{t}\left(H_{t}^{u}-H_{t-1}^{u}\right)+R_{t-1} B_{t-1}^{u}=B_{t}^{u}+Y_{t}^{u}
$$

Solving this problem yields first order conditions for consumption and housing, once one acknowledges that housing is like a durable good that never depreciates:

$$
\begin{aligned}
\left(C_{t}^{u}\right)^{-1 / \sigma} & =\beta R_{t} E_{t}\left(\left(C_{t+1}^{u}\right)^{-1 / \sigma}\right) \\
Q_{t}\left(C_{t}^{u}\right)^{-1 / \sigma} & =j u^{\prime}\left(H_{t}^{u}\right)+E_{t}\left(\beta Q_{t+1}\left(C_{t+1}^{u}\right)^{-1 / \sigma}\right) .
\end{aligned}
$$

\subsection{Constrained households}

The economy is also populated by a fraction $\zeta$ of constrained households, which assign a high weight to today's consumption and do not discount the future. In absence of a debt constraint, these households

\footnotetext{
${ }^{9}$ There is no uncertainty in the model: therefore, given rational expectations, agents have perfect foresight of the future.
} 
would accumulate infinite negative wealth. To make matters interesting, I assume there is a limit on their net obligations. The amount they can borrow cannot exceed a fraction $m \leq 1$ of the next period's expected value of real estate holdings discounted by the rate of interest. Their obligations $B_{t}^{c}$ are thus bound by:

$$
B_{t}^{c} \leq m E_{t}\left(Q_{t+1}\right) H_{t}^{c} / R_{t}
$$

In other words, lenders (unconstrained households) impose a margin requirement on borrowers of $1-m$. I do not try to derive this constraint endogenously. However, this kind of borrowing limit could arise for instance due to liquidation costs, if - in case of default - legal and other cost amount to a fraction $1-m$ of the house value. ${ }^{10}$

These households solve the following problem:

$$
\max \ln C_{t}^{c}+j^{c} u\left(H_{t}^{c}\right)
$$

The assumption of $\log$ utility in consumption here simplifies tractability without affecting the derivations below. So long as these agents do not give weight to the future, they end up being constrained in equilibrium. The assumption of a more general functional form for housing demand leaves open the possibility that housing demand changes more or less strongly as house prices change. Later, I will describe how one can obtain an estimate of the own price elasticity of housing demand for these agents.

Constrained households are subject to the borrowing constraint above (equation (3.5)) and to the following flow of funds:

$$
C_{t}^{c}+Q_{t}\left(H_{t}^{c}-H_{t-1}^{c}\right)+R_{t-1} B_{t-1}^{c}=Y_{t}^{c}+B_{t}^{c}
$$

Define $\Phi_{t}$ as the time $t$ shadow value of the borrowing constraint. The first-order conditions for an optimum are the consumption Euler equation and real estate demand:

$$
\begin{aligned}
1 / C_{t}^{c} & =\Phi_{t} R_{t} \\
Q_{t} / C_{t}^{c} & =j u^{\prime}\left(H_{t}^{c}\right)+E_{t}\left(\Phi_{t} m Q_{t+1}\right) .
\end{aligned}
$$

The equation for consumption and the housing demand equation differ from the usual formulations in two respects. On the one hand, there is no discounting, hence the marginal utility of future consumption does not

\footnotetext{
${ }^{10}$ Borrowing constraints of this form are by now standard in the macro literature. See Kiyotaki and Moore (1997) and Miles (1992 and 1995), for instance.
} 
appear. On the other, the marginal utility of consumption today is affected by $\Phi_{t}$, the Lagrange multiplier on the borrowing constraint. $\Phi_{t}$ equals the increase in lifetime utility that would stem from borrowing $R_{t}$ dollars today and consuming the proceeds, and reducing consumption by an appropriate amount next period (which costs nothing in terms of utility). ${ }^{11}$ One can notice that, since housing can be used as collateral, there is a distortion towards housing consumption in the model. Borrowing constraints affect the intertemporal allocation of resources as well as the within-period one, since real estate is both "good" and collateral.

Constrained households will borrow up to the limit and will be liquidity constrained in steady state (or in a neighborhood of it). In fact, the consumption Euler equation in the unconstrained households' problem guarantees that, in steady-state, the gross real interest rate is $R=1 / \beta$, the unconstrained household time preference rate. Combining this result with the steady state constrained households Euler equation for consumption yields: $\Phi=\beta / C^{\frac{1}{\sigma}}$. Therefore, the borrowing constraint in (3.5) will always hold with equality. ${ }^{12}$

\section{Deriving an Euler equation for aggregate consumption}

I consider the implications that the optimality conditions of this simple model for the purpose of deriving a relationship between house prices and aggregate consumption. Intuitively, near the steady state increases in house prices, by affecting borrowers credit capacity, will relax their borrowing constraints, lead to higher borrowing and increase in their consumption. This happens because borrowers marginal propensity to consume is higher than lenders' (which justifies why they became borrowers in the first place). On the other hand, changes in consumption for the lenders will be only driven by unexpected movements in the interest rate, which is a sufficient statistic for predicting consumption changes.

From now on, I linearize the model around the deterministic steady state and let lower-case letters denote percentage deviations from the steady state. That is, for each variable $X_{t}, x_{t} \equiv\left(X_{t}-X\right) / X$.

\footnotetext{
${ }^{11}$ See Zeldes (1989) for an insightful discussion of the interpretation of the Lagrange multiplier in the consumption Euler equation.

${ }^{12}$ In a neighborhood of the steady state, constrained households might want to hold a stock of assets as precautionary saving to insure again bad income shocks. Therefore, strictly speaking, if uncertainty is large there might be periods in which the borrowing constraint is not necessarily binding. If we confine ourselves to a perfect foresight equilibrium, we can neglect these issues.
} 
Aggregate consumption will be given by:

$$
c_{t}=\lambda c_{t}^{c}+(1-\lambda) c_{t}^{u}
$$

where $\lambda$ and $1-\lambda$ are the consumption shares of each group. ${ }^{13}$

For unconstrained households, the linearized Euler equation is standard, and is the one which has traditionally been tested in the literature beginning with Hall (1978). It states that, neglecting second order terms, consumption is negatively related to the long interest rate.

$$
c_{t}^{u}=E_{t} c_{t+1}^{u}-\sigma r_{t}
$$

For constrained households, the Euler equation holds with the addition of the multiplier on the borrowing constraint:

$$
c_{t}^{c}=-\phi_{t}-r_{t} .
$$

One can linearize the asset demand equation for borrowers/constrained agents to obtain: ${ }^{14}$

$$
q_{t}=m \beta E_{t} q_{t+1}-\theta(1-m \beta) h_{t}+m \beta \phi_{t}+c_{t}^{c}
$$

where $\theta$ is the long-run inverse elasticity of housing demand for the borrowers. This expression states that for borrowers housing demand is related to the marginal utility of housing as well as to the tightness of the borrowing constraint.

Combining and rearranging (4.3) and (4.4) yields:

$$
c_{t}^{c}=(1+\omega) q_{t}-\omega E_{t} q_{t+1}+\omega R_{t}+\theta h_{t}
$$

where $1+\omega=\frac{1}{1-m \beta}$ is the inverse of the downpayment needed to purchase one unit of housing. This expression formalizes how, for borrowers, consumption is a positive function of house prices, with a coefficient

\footnotetext{
${ }^{13}$ The consumption shares of each group $(\lambda$ and $1-\lambda)$ do not necessarily correspond to the mass of each group in the economy. The consumption shares depend on total income, on the mass of each group, as well as on the steady state net repayment which flows each period from borrowers to lenders. What I am able to identify in the empirical section is not the fraction of credit constrained consumers, but the fraction of consumption in total output of this group. This distinction is important because heterogeneity implies that income distribution matters in this economy.

${ }^{14}$ Define $\theta=-H^{c} u^{\prime \prime}\left(H^{c}\right) / u^{\prime}\left(H^{c}\right)$. Solving (3.8) for the value of the multiplier, plugging into (3.9) and linearizing around the non-stochastic steady state gives the equation in the text.
} 
that is equal to the inverse of the downpayment. Intuitively, by giving up one unit of consumption, a constrained agent can increase his housing demand by more than one, since the downpayment required to purchase one house is equal to $1 /(1-m \beta) .{ }^{15}$

The key insight here is that in a fully specified model one can express the multiplier on the borrowers' constraint as a specific function of observable variables. To the extent that the tightness of the borrowing constraint is related to current and expected house prices and to housing demand, these variables should be able to explain current consumption. ${ }^{16}$

The next step is to aggregate (4.2) and (4.5) across agents to obtain an approximate Euler equation for the aggregate economy. Summing across agents yields, after some algebra:

$$
c_{t}=(1-\lambda) E_{t} c_{t+1}^{u}-(\sigma(1-\lambda)-\omega \lambda) r_{t}+\lambda\left((1+\omega) q_{t}-\omega E_{t} q_{t+1}+\theta h_{t}\right) .
$$

One problem with this expression is that the conditional expectation of unconstrained consumption, $E_{t} c_{t+1}^{u}$, cannot be observed. However, leading (4.3) one period ahead and solving for $E_{t} c_{t+1}^{u}$ gives:

$$
E_{t} c_{t+1}^{u}=-\sigma E_{t} \sum_{i=0}^{\infty} r_{t+1+i}=-\sigma l_{t}
$$

where $l_{t}$ is the interest rate on a long term real rate (as opposed to $r_{t}$, which is the rate on one period bond). ${ }^{17}$ Therefore, after some algebra, I can write the aggregate consumption Euler equation as:

$$
c_{t}=-\psi_{1} l_{t}+\psi_{2} q_{t}-\psi_{3} E_{t} q_{t+1}+\psi_{4} r_{t}+\psi_{5} h_{t}
$$

In terms of the model structural parameters, the equation can be written as:

$$
c_{t}=-\sigma(1-\lambda)\left(r_{t}+l_{t}\right)+\omega \lambda\left(q_{t}+r_{t}-E_{t} q_{t+1}\right)+\lambda q_{t}+\theta \lambda h_{t}
$$

which explicitly takes into account the coefficient restrictions implied by the model. In particular, I can freely estimate only four coefficients, corresponding respectively to $\lambda, \sigma, \omega, \theta$.

\footnotetext{
${ }^{15}$ In the framework presented, I will not be able to identify $\beta$ and $m$ separately from the data. From now on, I aim at identifying $m \beta$ together.

${ }^{16}$ Studying the partial equilibrium problem of a liquidity constrained consumer, Pesaran and Smith (1995) propose to approximate the unknown Lagrange multipliers in the Euler equation by a general function of observable variables. My theory has the benefit of suggesting what these variables should be.

${ }^{17}$ More precisely, $l_{t}$ should represent the expected interest rate at time $t$ for time $t+1$ on a long term bond, that is $l_{t+1}$. In absence of a fully-fledged theory of the term structure, I prefer using $l_{t}$ rather than constructing an estimate of $l_{t+1}$.
} 
Since under rational expectations ${ }^{18}$ the error in the forecast of $q_{t+1}$ is uncorrelated with information dated $t$ and earlier, it follows from (4.9) that:

$$
E_{t}\left\{\left(c_{t}+\chi_{1}\left(r_{t}+l_{t}\right)-\chi_{2}\left(q_{t}+r_{t}-E_{t} q_{t+1}\right)-\chi_{3} q_{t}-\chi_{4} h_{t}\right) \mathbf{z}_{t}\right\}=0
$$

where $\mathbf{z}_{t}$ is a vector of variables dated $t$ and earlier (and, thus, orthogonal to the surprise in house prices in $t+1$ ). The above orthogonality condition forms the basis for estimating the model via generalized method of moments (GMM). Finally, the structural parameters can be recovered from the estimates of $\chi_{1}$ to $\chi_{4}$ in (4.10) using the following relationships: $\lambda=\chi_{3}, \sigma=\chi_{1} /\left(1-\chi_{3}\right), \omega=\chi_{2} / \chi_{3}$ and $\theta=\chi_{4} / \chi_{3}$.

\section{Testing the Euler equation}

I use quarterly US data for the period 1986:1 to 2002:4. The choice of the sample period reflects the restructuring and the behavior of the housing finance system over the last decades. Before the mid-1980s, the housing finance system was dominated by regulated, highly specialized savings institutions. After the mid-1980s, the housing finance market has moved to a system where mortgage institutions are less regulated, the mortgage market is largely integrated into the broader capital market, and constraints on the supply of credit have largely disappeared. Of course, while the changes have largely affected the secondary mortgage market, the primary mortgage market still requires that homeowners pledge their house as collateral for the debt. ${ }^{19}$

I use the log change in real personal consumption expenditure to measure consumption. ${ }^{20}$ The shortterm real interest rate is constructed as the difference between the quarterly 3-month Treasury Bill and the quarter on quarter change in the GDP deflator. ${ }^{21}$ The long real interest rate is the 10-Year Treasury

\footnotetext{
${ }^{18}$ The assumption of rational expectations is consistent with the theoretical model, where agents base their information on all available information at time $t$. Whether it is appropriate for the housing market is a different issue, which I gloss over here. The literature on housing price dynamics has debated whether house prices have only been driven only by fundamental demand and supply factors or whether it is possible to find evidence of bubbles and non-rational behavior in the housing market. A good survey of these issues is Cho (1996).

${ }^{19}$ See McCarthy and Peach (2002).

${ }^{20}$ Unless otherwise stated, all the data were taken from the FRED database. I use total consumption expenditure (thus including durable goods) because my aim is to assess the sensitivity of total consumption to movements in house prices.

${ }^{21} \mathrm{I}$ experimented using inflation in $t+1$ (and using the so constructed real interest rate measures as instruments from $t-2$ backwards). The results were very similar.
} 
Constant Maturity Rate minus change in log GDP deflator. The house price (logged and first differenced) is the Conventional Mortgage Home Price Index from Freddie MAC (deflated with the GDP deflator). Finally, I need to proxy for housing demand of the constrained agents: I assume that a valid measure of housing demand for these agents is total residential investment; this assumption is plausible, if one thinks that most of the investment in housing at the margin is done by first-home buyers, who are typically constrained. ${ }^{22}$

All the regressions that follow include an intercept term. The set of instruments is described below.

\subsection{Reduced form evidence}

I first report the estimate of Equation 4.8. I refer to this equation as 'reduced form', since it contains an estimate of the overall sensitivity of consumption to house prices, interest rates, and housing demand, but not of the structural parameters of the model. As instruments, I use four lags of each right-hand side variable. ${ }^{23}$ The resulting estimated equation (omitting the coefficient on the constant term) is given by (standard errors are in parentheses):

$$
c_{t}=\underset{(0.29)}{0.68} l_{t}+\underset{(0.11)}{0.47} q_{t}-\underset{(0.11)}{0.32} E_{t} q_{t+1}-\underset{(0.19)}{0.07} r_{t}+\underset{(0.02)}{0.11} h_{t}
$$

Overall, the estimated consumption Euler equation appears in line with reasonable priors. The coefficient on the long real interest rate is negative and significant, while the short term interest rate has limited explanatory power and is not significantly different from zero. Moreover, the coefficient on current house prices is large, positive and significant, while the coefficient on expected house prices is negative. Finally, the coefficient on $h_{t}$ is positive and significant.

The coefficients in (5.1) can be interpreted as elasticities, but with the following caveat. In the general equilibrium model that leads to this equation, changes in any of the variables on the right-hand side will in general induce offsetting movements in other variables on the right-hand side (or on the coefficients on these variables) so that aggregate consumption is unchanged. ${ }^{24}$ Think about financial liberalization, for instance. Financial liberalization boosts consumption of the borrowers in the short-run. In the long-run, however,

\footnotetext{
${ }^{22}$ The assumption here in other words is that first-time buyers, who are typically credit constrained, drive most of the variation in investment in new houses.

${ }^{23}$ Adding lagged consumption growth to the set of instruments did not affect the results. Like the structural equations estimated below, the equation is estimated via GMM methods.

${ }^{24}$ In the economy of the paper there is no aggregate saving, so total consumption always equals total income, which is exogenous.
} 
either consumption of the borrowers is permanently lower and consumption of lenders is permanently higher (so that $l_{t}$, the long-run interest rate, rises) or borrowers need to consume less housing ( $h_{t}$ is lower). In a general equilibrium model with production or nominal rigidities, one can argue that either $h$ or $l$ or $r$ do not change, or that they are sticky due to policy or adjustment lags. However, the key point is that (5.1) holds regardless of the structure of the economy, since it is derived only from a simple intertemporal optimization problem.

Keeping this in mind, one can loosely interpret the above coefficients as describing elasticities. One thing that stands out is that the sensitivity of consumption growth to current house prices is large, positive and significant. The long-run elasticity of consumption growth to house prices is smaller $(0.15=0.47-0.32)$ and appears reasonable. Interestingly, such a number is also in line (albeit a little on the high side) with the survey evidence presented above. Thus, at first pass, it appears that the new consumption Euler equation provides a reasonable description of consumption dynamics.

\subsection{Structural estimates}

I now redo the exercise in a way that permits to recover direct estimates of the structural parameters of the model, in particular $\lambda$, the share of consumption accruing to unconstrained agents, $1+\omega$, the approximate inverse of the down-payment needed to purchase a house, $\sigma$, the elasticity of substitution of the unconstrained agents, and $\theta$, which is related to the price elasticity of housing demand.

One issue I have to confront is the fact that the econometric specification is nonlinear in the structural parameters of interest. A well-known issue is that nonlinear estimation using GMM is, in small samples, sensitive to the way the orthogonality condition is normalized. The orthogonality condition I choose is the one of equation (4.10). However, I estimated this equation using alternative sets of instruments.

The specification takes the form:

$$
E_{t}\left\{\left(c_{t}+(1-\lambda) \sigma\left(r_{t}+l_{t}\right)-\omega \lambda\left(q_{t}+r_{t}-E_{t} q_{t+1}\right)-\lambda q_{t}-\theta \lambda h_{t}\right) \mathbf{z}_{t}\right\}=0
$$

[ Table 1 about here ]

Estimates of the structural parameters and their standard errors are reported in Table 1. I report results using four different sets of instruments. In all the regressions, I also use one lag of the ratio household 
debt over personal disposable income doy (constructed from the Flows of Funds accounts) as an instrument. In column (1), the instruments are four lags of $r, l, q, h$. In column (2), I use as instruments four lags of $(r+l),\left(q+r-q_{+1}\right),{ }^{25}(q)$ and $(h)$, thus directly translating into the set of instruments the restrictions of the model. In column (3) I also use four lags of consumption growth as an additional instrument. Because of time aggregation worries, in column (4) I use instruments dated $t-2$ and earlier, so that there is at least a two-period time gap between instruments and variables in the estimated equation. ${ }^{26}$ Although I do not report the results here, I also controlled for GDP or GDP growth in the specifications: the results were unchanged.

In all specifications, the results are similar. In general, the structural estimates tell the same story as the reduced form estimates.

The implied estimate of $\lambda$, the fraction of consumption accruing to constrained agents, ranges from 0.18 to 0.26 and is precisely estimated. Interestingly, this number is slightly smaller than the numbers reported by Campbell and Mankiw (1989), who estimate the fraction of constrained consumers to be in the neighborhood of 0.4 .

The model also provides an estimate of how an increase in house prices translates into a short-run increase in consumption by allowing more borrowing. Depending on the specification, the estimate of $\frac{m \beta}{1-m \beta}=\omega$ is between 1.33 and 1.94, and is significantly larger than zero in all cases but one. Given that the model is estimated at quarterly frequencies, I can recover $m$, the implied loan-to-value ratios, assuming $\beta=0.99$, as standard in the real business cycle literature. The implied estimate of $m$ is then comprised between 0.58 and 0.67. This estimate is quite sensible. While actual loan-to-value ratios for houses are somewhat higher (around $75-80 \%$ on average throughout the sample period, see for instance Gilchrist, 1997), they are within one standard error from the estimated coefficient. In addition, not all house prices changes lead to equity withdrawal. Moreover, actual lending criteria in the mortgage market are such that the borrower's income, besides collateral value, is a limiting factor in affecting the borrowing capacity of the agents and their ability to cash in equity gains. For these reasons, while the estimate of $m$ is perhaps smaller than one would expect, it is very much in line with reasonable priors.

\footnotetext{
${ }^{25}$ To get around endogeneity problems, I lag $q+R-q_{+1}$ twice.

${ }^{26}$ See Campbell and Mankiw (1989) for a discussion.
} 
The estimate of the intertemporal elasticity of substitution for the unconstrained agents is also in line with expectations, and ranges from 0.4 to 1 , which are all plausible. Finally, the range of estimates of $\theta$ goes from 0.44 to 0.67 . Taking the average value of 0.55 , this translates into a long-run price elasticity of housing demand for the constrained agents which is in the neighborhood of $1 / 0.55 \approx 2$. I am unaware of studies that estimate a similar parameter, but I do not consider this number to be unrealistic. $^{27}$

\subsection{Robustness analysis}

The model also works well in the sense that I do not reject the overidentifying restrictions. ${ }^{28}$

I now consider two robustness exercises. The first allows one lag of consumption to enter the right-hand side of the consumption Euler equation. The second explores a candidate proxy for income surprises in the Euler equation, in the spirit of Muellbauer (1983).

I add lagged consumption to the baseline case (equation (4.9)). Some studies (for instance Fuhrer and Rudebusch, 2004) have recently criticized the standard consumption Euler equation on ground that it implies "too much" forward-looking behavior. The model here implies that agents place a substantial weight on expected future variables in determining their consumption choices. However, the weight on the future that seems consistent with both the aggregate time series data and theoretical models has been the subject of much debate. To account for this possibility, I estimate equation (4.9) allowing for one lag of consumption (since the estimates did not change much using additional lags, I only report the results for the one-lag case). In other words, I estimate:

$$
c_{t}=\rho c_{t-1}-\sigma(1-\rho)(1-\lambda)\left(r_{t}+l_{t}\right)+\omega \lambda(1-\rho)\left(q_{t}+r_{t}-E_{t} q_{t+1}\right)+\lambda(1-\rho) q_{t}+\theta \lambda(1-\rho) h_{t}
$$

Table 2 reports the results. The parameter $\rho$ denotes the weight on lagged consumption in the Euler equation. Since the estimates do not change much across the various specifications, I only report the results using the instruments of column 1 of Table $1 .{ }^{29}$ The overall effect of lagged consumption is quite small: the estimate of $\rho$ is only 0.09 , thus implying that forward looking behavior dominates.

\footnotetext{
${ }^{27}$ For the aggregate economy, empirical studies find however lower numbers (the point estimate seems to be around 0.6 ) for the long-run price elasticity of housing demand (see the survey by Olsen, 1987, for instance).

${ }^{28} \mathrm{Only}$ in same specifications the point estimates tend to be slightly sensitive to the maximum lags of instruments included, as well as to the choice of the starting sample period.

${ }^{29}$ Lagged consumption growth was also included among the instruments.
} 
[ Table 2 about here ]

Finally, I consider another variable that might have predicted power for consumption growth, namely the change in unemployment expectations from the University of Michigan's consumer sentiment survey $(\Delta u) \cdot{ }^{30}$ That is:

$$
c_{t}=-\sigma(1-\lambda)\left(r_{t}+l_{t}\right)+\omega \lambda\left(q_{t}+r_{t}-E_{t} q_{t+1}\right)+\lambda q_{t}+\theta \lambda h_{t}-\zeta \Delta u_{t(-1)}
$$

This variable might capture changes in economic uncertainty that act as shifters of the marginal utility of consumption. I add this variable as an additional regressor to (4.9), either current (column 2) and lagged (column 3): ${ }^{31}$ as expected, the variable enters the regression with a negative sign and is statistically significant; as for the estimates of the other parameters, they are in line with the results of Table 1, although they are somewhat less precisely estimated. The only exception is the coefficient $\lambda$, which is estimated very precisely, although it is smaller than the numbers in Table 1 when the current value of $\Delta u$ is used.

\section{Conclusions}

My results suggest that the Euler equation for consumption with borrowers whose credit capacity is constrained by their collateral values may provide a reasonably good description of consumption dynamics.

It is interesting to relate my findings to the study by Jappelli and Pagano (1989). They study across countries how the sensitivity of consumption to current income is positively related to the size of capital market imperfections, as proxied by the loan-to-value ratios. They find that lower loan-to-value ratios lead to lower consumer debt, which in turn increases the sensitivity of consumption to current income. My structural econometric approach takes a slightly different route: first of all, I regard housing values more informative than income at the margin for the collateral capacity of the agents. Therefore, I can study the excess sensitivity of consumption to house prices, rather than to income. Secondly, since my estimation is backed by a fully-fledged general equilibrium model, I can recover directly estimates of $m$, the loan-to-value ratios, from the estimates of the elasticity of consumption to house prices, and still identify separately $\lambda$, the share of consumption attributable to constrained consumers, and $m$. My emphasis is in the distinction between

\footnotetext{
${ }^{30}$ This variable can capture changes in economic uncertainty that might have predictive power for consumption growth. See Campbell and Mankiw (1989).

${ }^{31}$ Four lags of $\Delta u$ were used as additional instruments in the regressions with the unemployment expectations variable.
} 
estimation of $\lambda$ and estimation of $m$, something that the earlier literature has not emphasized. Casual observation of the US experience over the last decades suggests that $\lambda$ might have fallen over time, but $m$ might have increased, thus explaining a potentially large feedback from house price changes to consumption even in presence of a shrinking group of constrained agents.

To understand how house prices interact with consumption, in other words, requires two ingredients: first, a model with heterogenous agents; second, an environment that specifies the link through which home equity gains can be transferred into higher borrowing and higher consumption. Earlier studies have deepened our understanding of the first step. This paper tries to close the gap with the second.

One important avenue to investigate involves looking at the trend as well as the cyclical behavior of the loan-to-value ratios. The assumption of a constant loan-to-value ratio might be at odds with the data over long periods, ${ }^{32}$ especially since financial liberalization has led over time to an increase in the loan-to-value ratios for home-buyers, as well as to increased possibilities to cash in housing wealth for households. Indeed, as emphasized in the introduction, recent years have seen a rapid increase in both home lines of credit and traditional home equity loans, which have increased the liquidity of housing. It would be interesting to see whether extensions of the present framework along these lines can provide a better fit of the data.

Of course, one drawback of the Euler equation studied here is that such approach, being based on a simple optimality condition between two adjacent points in time, cannot say much about how consumption reacts to unexpected changes in house prices, although this issue is of paramount importance. The fact that the simple model presented here gives reasonable estimates of the structural parameters, however, suggests that extensions along this dimension in order to derive a closed-form "consumption function" should be worth investigating. This issue is left for future research.

\footnotetext{
${ }^{32}$ On this issue, see also Bandiera et al. (2000).
} 


\section{References}

[1] Aoki, K., Proudman J., Vlieghe J., 2001. Houses as Collateral: Has the Link between House Prices and Consumption Changed?, mimeo, Bank of England.

[2] Attanasio, O., Low, H., 2004. Estimating Euler Equations, Review of Economic Dynamics, forthcoming.

[3] Bacchetta, P., Gerlach, S., 1997. Consumption and Credit Constraints: International Evidence, J. Monet. Econ., 40. 207-238.

[4] Bandiera, O., Caprio, G. Jr., Honohan, P., Schiantarelli, F., 2000. Does Financial Reform Raise or Reduce Savings?, Rev. Econ. Statist., 82, 2, 239-263.

[5] Bernanke, B.S., Gertler, M., 1995. Inside the Black Box: The Credit Channel of Monetary Policy Transmission, J. Econ. Perspect., 9, 4, 27-48.

[6] Black, J.M., de Meza, D., Jeffreys, D., 1996. House prices, the supply of collateral and the enterprise economy, Econ. J., Jan.

[7] Campbell, J.Y., Mankiw, N.G., 1989. Consumption, Income, and Interest Rates: Reinterpreting the Time-Series Evidence, in NBER Macroeconomics Annual.

[8] Campbell, J.Y., Mankiw, N.G., 1991. The Response of Consumption to Income. A Cross Country Investigation, Europ. Econ. Rev., 35, 723-767.

[9] Caporale, G., Williams G., 2001. Monetary policy and financial liberalization: the case of United Kingdom consumption, J. Macroecon., 23, 1, 177-197.

[10] Carroll, C.D., 2001. A Theory of the Consumption Function, With and Without Liquidity Constraints, NBER Working Paper 8387.

[11] Carroll, C.D., 2004. Housing Wealth and Consumption Expenditure, mimeo.

[12] Case, K.E., Quigley, J.M., Shiller, R.J., 2003. Comparing Wealth Effects: The Stock Market versus the Housing Market, Cowles Foundation Discussion Paper No.1335. 
[13] Chah, E.Y., Ramey, V.A., Starr, R.M., 1995. Liquidity Constraints and Intertemporal Consumer Optimisation: Theory and Evidence from Durable Goods, J. Money, Credit, Banking, 27, 1, 272-287.

[14] Cho, M., 1996. House Price Dynamics: A Survey of Theoretical and Empirical Issues, J. Housing Res., $7,2,145-171$.

[15] Davis, M., Heathcote, J., 2003. Housing and the Business Cycle, mimeo.

[16] Davis, M., Palumbo, M., 2001. A Primer on the Economics and Time Series Econometrics of Wealth Effects, FEDS Working Paper.

[17] Fuhrer, J., Rudebusch, G.D., 2004. Estimating the Euler Equation for Output, J. Monet. Econ., in press.

[18] Gilchrist, S., 1997. Unemployment Expectations, Jumping (S,s) Triggers, and Household Balance Sheets: a Comment, in NBER Macroeconomics Annual.

[19] Hall, R., 1978. Stochastic implications of the life cycle-permanent income hypothesis: theory and evidence, J. Polit. Economy, 86, 6, 971-87.

[20] Hansen, L.P., 1982. Large Sample Properties of Generalized Method of Moment Estimators, Econometrica, 50, 1029-54.

[21] Iacoviello, M., 2002. House Prices, Borrowing Constraints and Monetary Policy in the Business Cycle, Boston College working paper n. 542.

[22] Jappelli, T., Pagano, M., 1989. Aggregate consumption and capital market imperfections: an international comparison, Amer. Econ. Rev., 79, 5, 1088-1105.

[23] Kiyotaki, N., Moore, J., 1997. Credit Cycles, J. Polit. Economy, 105, 2, 211-48.

[24] McCarthy, J., Peach, R.W., 2002. Monetary policy transmission to residential investment, Econ. Pol. Rev., 139-161.

[25] Miles, D., 1992. Housing Markets, Consumption and Financial Liberalisation in the Major Economies, Europ. Econ. Rev., 36, 5, 1093- 1127. 
[26] Miles, D., 1995. Housing, financial markets and the wider economy, John Wiley and Sons, New York.

[27] Muellbauer, J., 1983. Surprises in the consumption function. Econ. J., 93, Conference Papers, 34-50.

[28] Olsen, E. O., 1987. The Demand and Supply of Housing Service: A Critical Survey of the Empirical Literature, in Handbook of Regional and Urban Economics, Volume II, ed. E.S. Mills, Elsevier Science Publications, 989-1022.

[29] Parker, J., 2000. Comment on: Real Estate and the Macroeconomy, Brookings Pap. Econ. Act., 2, $150-58$.

[30] Pesaran, H., Smith, R.P., 1995. The Role of Theory in Econometrics, J. Econometrics, 67, 61-79

[31] Piazzesi, M., Schneider, M., Tuzel, S., 2003. Housing, Consumption, and Asset Pricing, mimeo.

[32] Zeldes, S.P., 1989. Consumption and Liquidity Constraints: An Empirical Investigation, J. Polit. Economy, 97, 2, 305-346. 
Table 1

Estimates of the consumption Euler equation: GMM estimates ${ }^{a}$

\begin{tabular}{|c|c|c|c|c|}
\hline \multicolumn{5}{|c|}{ Dependent variable: $\Delta \ln$ consumption } \\
\hline Estimates & (1) & $(2)$ & $(3)$ & $(4)$ \\
\hline \multirow[t]{2}{*}{$\lambda$} & 0.26 & 0.22 & 0.18 & 0.22 \\
\hline & $(0.08)$ & $(0.09)$ & $(0.06)$ & $(0.13)$ \\
\hline \multirow[t]{2}{*}{$\sigma$} & 0.63 & 0.55 & 0.40 & 1.00 \\
\hline & $(0.17)$ & $(0.16)$ & $(0.10)$ & $(0.24)$ \\
\hline \multirow[t]{2}{*}{$\omega$} & 1.33 & 1.70 & 1.68 & 1.94 \\
\hline & $(0.67)$ & $(1.07)$ & $(0.90)$ & $(2.00)$ \\
\hline \multirow[t]{5}{*}{$\theta$} & 0.44 & 0.52 & 0.67 & 0.55 \\
\hline & $(0.16)$ & $(0.26)$ & $(0.25)$ & $(0.34)$ \\
\hline & $r_{t-1}, \ldots r_{t-4}$ & $(r+l)_{t-1} \cdots t-4$ & $c_{t-1}, \ldots c_{t-4}$ & $c_{t-2}, . . c_{t-4}$ \\
\hline & l. & & $r_{t-1}, . . r_{t-4}$ & $r_{t-2}, . . r_{t-4}$ \\
\hline & & & $l_{t-1}, . . l_{t-4}$ & $l_{t-2}, . . l_{t-4}$ \\
\hline \multirow{4}{*}{ Instruments } & $q_{t-1}, . . q_{t-4}$ & $q_{t-1}, . . q_{t-4}$ & & \\
\hline & $h_{t-1}, \ldots h_{t-4}$ & $h_{t-1}, . . h_{t-4}$ & & $q_{t-2}, . . q_{t-4}$ \\
\hline & & & $h_{t-1}, . . h_{t-4}$ & $h_{t-2}, . . h_{t-4}$ \\
\hline & $\operatorname{aog}_{t-1}$ & $\operatorname{wog}_{t-1}$ & $\operatorname{doy}_{t-1}$ & $d o y_{t-2}$ \\
\hline$j$-statistic & 0.10 & 0.10 & 0.15 & 0.10 \\
\hline
\end{tabular}

${ }^{a}$ : The table reports GMM estimates of the structural parameters of Eq. (4.10). Estimates are based on quarterly data over the period 1986:1 - 2002:4. Robust standard errors are reported in parentheses. The last row reports the p-value associated with Hansen's (Hansen, 1982) $j$-test of the model's overidentifying restrictions. 
Table 2

Robustness analysis ${ }^{a}$

\begin{tabular}{|c|c|c|c|}
\hline Estimates & (1) & $(2)$ & (3) \\
\hline \multirow[t]{2}{*}{$\lambda$} & 0.26 & 0.10 & 0.25 \\
\hline & $(0.09)$ & $(0.08)$ & $(0.06)$ \\
\hline \multirow[t]{2}{*}{$\sigma$} & 0.83 & 0.51 & 0.60 \\
\hline & $(0.25)$ & $(0.13)$ & $(0.15)$ \\
\hline \multirow[t]{2}{*}{$\omega$} & 1.77 & 2.53 & 1.02 \\
\hline & $(1.02)$ & $(2.72)$ & $(0.46)$ \\
\hline \multirow[t]{2}{*}{$\theta$} & 0.44 & 1.01 & 0.26 \\
\hline & $(0.19)$ & (1.08) & $(0.09)$ \\
\hline \multirow[t]{2}{*}{$\rho$} & 0.09 & & \\
\hline & $(0.08)$ & & \\
\hline \multirow[t]{2}{*}{$\zeta_{\text {current }}$} & & 0.02 & \\
\hline & & (0.008) & \\
\hline \multirow[t]{2}{*}{$\zeta_{\text {lagged }}$} & & & 1.32 \\
\hline & & & $(0.18)$ \\
\hline$j$-statistic & 0.09 & 0.12 & 0.12 \\
\hline
\end{tabular}

${ }^{a}$ : The table reports GMM estimates of various version of Eq. (4.10). Estimates are based on quarterly data over the period 1986:1 - 2002:4. Robust standard errors are reported in parentheses. The first column adds lagged consumption growth to the regressors; column (2) adds current change and column (3) adds lagged change in unemployment expectations. The last row reports the p-value associated with Hansen's (Hansen, 1982) $j$-test of the model's overidentifying restrictions. 